\title{
A Case Study on the Effects of Mnemonics on English Vocabulary
}

\author{
Mohd Nazri Latiff Azmi (Corresponding author) \\ Faculty of Languages and Communication, Universiti Sultan Zainal Abidin, Gong Badak Campus, 21300 Kuala Nerus, Terengganu, Malaysia \\ E-mail:mohdnazri@unisza.edu.my \\ Muhammad Hadi Syafiq Mohd Najmi \\ Faculty of Languages and Communication, Universiti Sultan Zainal Abidin, Gong Badak Campus, 21300 Kuala Nerus, Terengganu, Malaysia \\ E-mail: hadi.syafiq@yahoo.com \\ Nurazan Mohmad Rouyan \\ Faculty of Languages and Communication, Universiti Sultan Zainal Abidin, Gong Badak Campus, 21300 Kuala Nerus, Terengganu, Malaysia \\ E-mail: nurazan@unisza.edu.my
}

Received: 15-08-2016

Published: 10-12-2016
Accepted: 11-10-2016

doi:10.7575/aiac.ijalel.v.5n.7p.178
Advance Access Published: November 2016

URL: http://dx.doi.org/10.7575/aiac.ijalel.v.5n.7p.178

\begin{abstract}
This case study examines the effectiveness of using mnemonic techniques in learning English vocabularies. This study looks into students' perspectives and point of view of the mnemonic technique in teaching and learning English vocabularies. The selected respondents are students who are currently learning English subject in a primary school. Their English teachers will teach the students about English vocabulary with and without using the mnemonic technique. A set of questionnaire will be given to the students. The result received from the questionnaire will be used to help in obtaining the data for the research. The aim of this study is to know the effectiveness of using mnemonic techniques in learning English vocabularies as well as the students' response towards the technique. This research will help to recommend future English teachers with guidance and thoughts that should be taken into consideration when teaching English vocabularies to their students.
\end{abstract}

Keywords: mnemonics, vocabulary, second language learning

\section{Introduction}

The importance of the vocabulary teaching is recognized by English teachers in generally speaking. The acquisition of vocabulary has been an ignored section in second language acquisition (Nunan, 1991; Meara, 1996). This situation continues until that kind of interest is reawakened during the recent decade (Chan, 2000). Hence, researchers have an interest in vocabulary improvement which leads them to review possible learning strategies aiming at identifying beneficial language strategies (Wenden \& Rubin, 1987; O'Malley \& Chamot, 1990; Oxford, 1990; Brown \& Perry, 1991; Gu \& Johnson, 1996; Hatch \& Brown, 1995).

An attempt has been made to capitalize on strategies that may bring about desirable vocabulary gains to second language learners (Chan, 2000) where researchers categorizing and comparing good language learners and unsuccessful learners. This can be connected with the experience of Hauptmann (2004) when he stated that adults who failed foreign language will blame the teachers, and teachers will blame the learners on their lack of hard work and way of learning. Thus, this kind of problem can be solved if the precaution steps are taken from the level of primary school. This experience is supported by observation from Benge and Robbins (2009) when their students cannot maintain the vocabulary taught by "the dictionary method". The students rarely can maintain their knowledge of the word even if the students learn the definition long enough to do well on the weekly test unless provided long-term support (Allen, 1999; Beck et al., 2013). Based on these two points, we know that one of the most basic elements of conquering the English language is vocabulary. We cannot express anything in English, not to say write a good article or talk with foreigners in English without vocabulary. Therefore, a new technique should be introduced so that students can find it easier to memorize new vocabulary, and the adult problem in mastering foreigner language can be solved from the primary school level.

Another problem is students need a certain amount of vocabulary to be mastered before they can move on to language proficiency and a lot of laboratory researches are done in order to get the result. Still, students are struggling to achieve the expected results (Zhang Guiping, 1996; Ma, 2009). The problem of mastering a large vocabulary expansion by the second language learners who reach the intermediate stage are referred as the main reason of giving up their effort (Winitz, 1978). This also affects the students to be not able to expand the ability to integrate the link between past information with the new item (Craik \& Lockhart, 1972). Therefore the mnemonic technique is chosen to test the 
objective of this study whether teachers can guide students as an alternative way to make the learning session to be more joyful, efficient, and effective (Deconinck et al., 2010; Kelly \& Li, 2005).

A mnemonic is explained by Hayes (2009) that it is a formulate design to support memory and students can encode better data by using the mnemonic order, so that it is easier to remember later on. Learners can be helped by mnemonic devices to recall bigger pieces of info especially in the form of list like characteristics, steps, stages, parts, etc. (Congos, 2011). Students who need help understanding the concept will benefit from instruction in comprehensive strategies. A mnemonic device becomes an instrument to construct threads from new to old ideas for students with memory challenges and processing disorders (DeLashmutt, 2007).

Congos (2011) believed mnemonic techniques help learners to remember larger pieces of information, especially in the form of lists like characteristics, steps, stages, parts, phases, etc. He found that mnemonic can increase recalls, as the students who usually use the mnemonic technique have increased their test marks up to 77\% (Miller, 1993).

Students nowadays mostly have problem with memorizing English words especially the jargons. This is due to they are not using the English language in daily life communication even in the English class. This situation has caused the level of their English command is lower compared to the students who use a lot of English language even after the English class at their school.

Therefore, the researchers carried out this research to see how effective the mnemonic technique in helping the students memorizing the English vocabulary, since their English level is not so good compared to the students who practice English even outside of the school compound. Thus, there is a technique which is called mnemonic. As stated by Hayes (2009), students will get tools given mnemonic instructions to better information encoding, so that it is easier to recall later on. However, the mnemonic techniques are not the replacements for studying. It just assists in recalling information with the condition that the data are already being in memory somewhere (Spackman, 2009).

This mnemonic appears to be an effective strategy for increasing student's comprehension test scores which made mnemonics become important (DeLashmutt, 2007). Based on the belief that mastery of a reasonably rich vocabulary in the target language not only would benefit the learners with competence in understanding and manipulating instructional materials written in the target language across the school curriculum. But also with competence in the target language itself, a number of studies (Pressley et al., 1982; Brown \& Perry, 1991; Joe, 1998) have been conducted on various methods of second language vocabulary learning. Hence, the mnemonic will be used in this research in order to find out its effectiveness in learning English vocabulary among the primary school students. The main research objective of this study is to identify the impacts of using mnemonics in learning English vocabulary among primary school students.

\section{Literature Review}

According to a study conducted by Benge and Robbins (2009), they carried out a research on the effect of mnemonic to their students to close the performance gap between the students who are able readers and students who are struggling readers in learning the English vocabulary. Thus, in order to achieve their objectives, they have tested their students whether they can recall back the English vocabulary that they have learned so far with and without the picture review which provided by them. The result is really impressive as the average retention rate of the students have increased from $73.6 \%$ to $82.5 \%$ after they get the fifteen minutes review from the pictures provided for each word.

It believes that a firm link can be developed with the help of mnemonic or the keyword method between the new vocabulary items. It means that it enables learners to retrieve the appropriate word better at the right moment. The learners can love the autonomy of employing either the imagery or the sentence, whichever snaps into mind and seems to be the most ordinary way of creating the association (Chan, 2000). Since the overview of the mnemonic method by Atkinson (1975) and his colleagues as an effective supplementary method for foreign vocabulary learning, several studies have stated that the mnemonic method is great for vocabulary learning to other traditional methods like the context method (Thompson, 1987).

Lorayne and Lucas (1974) claim that occasionally refreshing the image by retrieving it helps reinforcing the memory such that it can be recalled for as long as necessary. It is also necessary for the mnemonic instruction to be important because it is a good way to increase the student comprehension test scores (Spackman, 2009). Scruggs and Mastropieri (2000) recommend that the reason comprehension scores are higher for students by using mnemonic strategies is that the strategies improve their ability to remember the factual information required to answer comprehension question. Finally, it says that a strategy that gives a visual or verbal prompt for students who may have difficulty recalling information is the reason why educators should care about mnemonic instruction.

Another past research that shows the performance increase among students is the research by DeLashmutt (2007) entitled "A Study of the Role of Mnemonics in Learning Mathematics". It is about the usage of mnemonic techniques for the students to learn mathematics in effective way. It is stated that the reason mnemonic instruction is important because it appears to be an effective approach for improving student comprehension test scores. It is also suggested that the students who use mnemonic techniques will get higher comprehension scores because the strategies improve their ability to memorise the factual information needed to answer comprehension question.

Anjomafrouzi and Tajalli (2012) have done a research on "Effects of Using Mnemonic Associations on Vocabulary Recall of Iranian EFL Learners over Time". It is to study the effects of using mnemonic associations on vocabulary recall of Iranian EFL in two separate experiments with adolescents and adults. The students are divided into two groups 
of experimental (mnemonics) and control (note). The data shows that a better performance of adult students is created with the use of mnemonic associations compared to the external control (rote group) and internal control group (when students used no association in mnemonics group) (Anjomafrouzi \& Tajalli, 2012). The higher performance of mnemonic groups who regularly reported using initial relations shows that initial associations have a significant part at vocabulary recall of students. The vocabulary recall of adult students is also affected by mnemonic methods for both receptive and productive learning.

The introduction of mnemonic techniques to the students made them realize that it can strengthen their memory. A strong memory means that students can store and transfer information from Short Term Memory (STM) into Long Term Memory (LTM). According to the study made by Sarcoban and Basibek (2012), mnemonic methods specifically promotes vocabulary retention of the elementary level of EFL. Thus, they concluded that mnemonic techniques are suitable for leading the memory to longer term retention of the vocabulary items of elementary and true beginner language learners.

Mnemonic strategies are considered as an effective approach where there are forms of effective acoustic-imaginal-link can be created in the middle of stimulus and response. Encoding and retrieving mnemonically learned information that related to different information-processing demands as suggested by documentation of response latencies, differential serial position effects (Erten, 2008) and strategy reports (Scruggs \& Mastropieri, 2000).

\section{Methodology}

This applied science research was conducted in a primary school in Malaysia where the researchers wanted to investigate the effectiveness and impacts of using mnemonic techniques in learning English vocabulary among primary school students, and the opinion of students regarding this learning technique. This means that the researchers would be using the facts and information that are already available in the books, journal and the internet as the guidelines to analyze the findings. The researchers also used several opinions from other researchers as main reference.

This research is a mix-mode research triangulation which uses numerical value, words and sentences as the method of analysis. The researcher uses a questionnaire which has been designed by Chan (2000) as the main reference to modify it, so that it can be used to achieve the research objective as the method of collecting the data.

The data collected by questionnaire were coded and analyzed by using Statistical Package for the Social Science (SPSS) software, while the open ended questions were analyzed by using open coding. Furthermore, the researchers had made an observation to record the reaction of the students while learning through mnemonic and during answering the questionnaire. The data were presented and analyzed through a descriptive and statistical presentation for the questionnaire and an explanation for the qualitative data. A total of 33 respondents were chosen from a class of Standard Five students to be the samplings of the test. The researchers also asked the help of the English teachers to teach English vocabulary by using common way and mnemonic devices. The students were given a set of prepared questionnaires after each of the teaching and learning session was finished. The researchers also made observations during the learning and activity session.

\section{Data analysis and findings}

The important and relevant findings are tabled and discussed in the tables below.

Table 1. Students who have Problems in Memorizing English Words

\begin{tabular}{llcccc}
\hline & Frequency & Percent & Valid percent & Cumulative percent \\
\hline Valid & Strongly disagree & 2 & 6.1 & 6.1 & 6.1 \\
& Disagree & 6 & 18.2 & 18.2 & 24.2 \\
& Neither agree nor disagree & 18 & 54.5 & 54.5 & 78.8 \\
Agree & 6 & 18.2 & 18.2 & 97.0 \\
Strongly agree & 1 & 3.0 & 3.0 & 100.0 \\
Total & 33 & 100.0 & 100.0 & \\
\hline
\end{tabular}

Table 1 shows the percentage of the respondents' answers whether they have problems in memorizing English words. Based on the data analyzed, about $18.2 \%$ of the respondents disagree that they have problems in memorizing English words, and even $6.1 \%$ of them strongly disagree with this matter. Besides that, there are $18.2 \%$ of the respondents agree and $3 \%$ of the respondents strongly agree that they have some problems in memorizing English words. However, the majority of the students with the amount of $54.5 \%$ neither agrees nor disagree that they have some problems in memorizing English words. This shows that the majorities of the students neither agree nor disagree on having some problems in memorizing English words. 
Table 2. Students Know what Mnemonic is and its Function

\begin{tabular}{llcccc}
\hline & Frequency & Percent & Valid percent & $\begin{array}{c}\text { Cumulative } \\
\text { percent }\end{array}$ \\
\hline Valid & Disagree & 4 & 12.1 & 12.1 & 12.1 \\
& Neither agree nor disagree & 6 & 18.2 & 18.2 & 30.3 \\
& Agree & 12 & 36.4 & 36.4 & 66.7 \\
& Strongly agree & 11 & 33.3 & 33.3 & 100.0 \\
Total & 33 & 100.0 & 100.0 & \\
\hline
\end{tabular}

The next statement is to check whether the students know what mnemonic is and its function. The highest percentage of the respondents' answer is to agree with the statement which represents the $36.4 \%$ of the answer and another $33.3 \%$ of respondents are strongly agreed with the statement. However, about $18.2 \%$ of the respondents choose neither agree nor disagree for this statement and the lowest percentage is $12.1 \%$ of respondents which disagree that they know about mnemonic and its function. This means that most of the Standard Five students do know about what is mnemonic and its function, and only a few of the respondents do not know about mnemonic and its function.

Table 3. When Having Difficulties in English for the First Time Students Guess the Word

\begin{tabular}{|c|c|c|c|c|c|}
\hline & & Frequency & Percent & Valid percent & Cumulative percent \\
\hline \multirow[t]{6}{*}{ Valid } & Strongly disagree & 3 & 9.1 & 9.1 & 9.1 \\
\hline & Disagree & 5 & 15.2 & 15.2 & 24.2 \\
\hline & Neither agree nor disagree & 12 & 36.4 & 36.4 & 60.6 \\
\hline & Agree & 9 & 27.3 & 27.3 & 87.9 \\
\hline & Strongly agree & 4 & 12.1 & 12.1 & 100.0 \\
\hline & Total & 33 & 100.0 & 100.0 & \\
\hline
\end{tabular}

Furthermore, the next statement is to identify whether the respondents guess the word whenever they encounter new or difficult words in English for the first time. The highest percentage is 36.4\% which most of respondents neither agree nor disagree with the statement. However, there are $27.3 \%$ of the respondents choose to agree with guessing the words whenever they encounter new or difficult English words for the first time, and $12.1 \%$ of the respondents even strongly agree about this. There are $15.2 \%$ of the respondents choose to disagree, and another $9.1 \%$ choose strongly disagree in guessing the word whenever they encounter with new or difficult English words for the first time. Clearly, when encountered with new or difficult English words for the first time, most of the respondents do guess the meaning of the word.

Table 4. When Having Difficulties in English Words for the First Time Students Use Dictionary to Find its Meaning

\begin{tabular}{llcccc}
\hline & Frequency & Percent & Valid percent & Cumulative percent \\
\hline Valid & Disagree & 1 & 3.0 & 3.0 & 3.0 \\
& Neither agree nor disagree & 21 & 63.6 & 63.6 & 66.7 \\
& Agree & 4 & 12.1 & 12.1 & 78.8 \\
& Strongly agree & 7 & 21.2 & 21.2 & 100.0 \\
Total & 33 & 100.0 & 100.0 & \\
\hline
\end{tabular}

Statement 5 is to analyze whether the respondents choose to use a dictionary to find the words' meaning whenever they encounter new or difficult English words for the first time. The highest percentage is $63.6 \%$, which most of the respondents choose neither agree nor disagree that they will use a dictionary to find the meaning of new or difficult English words. About $21.2 \%$ of the respondents are strongly agree, and $12.1 \%$ of the respondents agree that they will use a dictionary to find the meaning of new or difficult English words encountered for the first time. However, only 3\% of the respondents choose to disagree with the statement. This shows that most of the Standard Five students neither agree nor disagree with using the dictionary whenever they encounter new or difficult English words for the first time.

Table 5. Students Love the Mnemonics Techniques More Compared to the Normal Teaching Technique

\begin{tabular}{llcccc}
\hline & Frequency & Percent & Valid percent & Cumulative percent \\
\hline Valid & Neither agree nor disagree & 2 & 6.1 & 6.1 & 6.1 \\
& Agree & 9 & 27.3 & 27.3 & 33.3 \\
& Strongly agree & 22 & 66.7 & 66.7 & 100.0 \\
& Total & 33 & 100.0 & 100.0 & \\
\hline
\end{tabular}


Section B consists of questions made to identify the impacts of mnemonic technique in learning English vocabulary. The first statement in this section is to identify whether the respondents love the mnemonic techniques more compared to the normal teaching technique. About $66.7 \%$ of the respondents strongly agree that they love the mnemonic techniques more compared to the normal teaching techniques, and $27.3 \%$ of the respondents also choose to agree with this statement. However, there are still $6.1 \%$ of the respondents who neither agree nor disagree with the statement. Thus, it is clearly shown that the majority of the respondents love the mnemonic techniques more compared to the normal teaching techniques.

Table 6. Students can Memorize More English Words with the Mnemonic

\begin{tabular}{llcccc}
\hline & Frequency & Percent & Valid percent & Cumulative percent \\
\hline Valid & Disagree & 2 & 6.1 & 6.1 & 6.1 \\
& Neither agree nor disagree & 9 & 27.3 & 27.3 & 33.3 \\
& Agree & 10 & 30.3 & 30.3 & 63.6 \\
& Strongly agree & 12 & 36.4 & 36.4 & 100.0 \\
Total & 33 & 100.0 & 100.0 & \\
\hline
\end{tabular}

The next statement is about whether the respondents can remember more English words with the mnemonic. The highest percentage for this statement is $36.4 \%$ of the respondents strongly agree that they can memorize more English words with the mnemonic. About $30.3 \%$ of the respondents agree with this matter, while $27.3 \%$ of the respondents neither agree nor disagree that they can memorize more English words with the mnemonic. However, there are also $6.1 \%$ of the respondents who disagree that they can memorize more English words with mnemonic which is the lowest among all of the respondents. This suggests that most of the respondents agree and strongly agree that they can memorize more English words with the mnemonic.

Table 7. Students can Memorize English Words Faster with Mnemonic

\begin{tabular}{llcccc}
\hline & Frequency & Percent & Valid percent & Cumulative percent \\
\hline Valid & Neither agree nor disagree & 6 & 18.2 & 18.2 & 18.2 \\
& Agree & 16 & 48.5 & 48.5 & 66.7 \\
& Strongly agree & 11 & 33.3 & 33.3 & 100.0 \\
& Total & 33 & 100.0 & 100.0 & \\
\hline
\end{tabular}

In the next statement, it says that students can memorize English word faster with mnemonic. About $48.5 \%$ of the respondents agree that they can memorize English words faster with mnemonic which is also the highest percentage among all of the respondents. Next are 33.3\% of the respondents add up with their choice of strongly agree which they can memorize English words faster with mnemonic. The lowest percentage of the respondents is $18.2 \%$, where the respondents neither agree nor disagree with the statement. These findings point out the fact that the majority of the respondents does agree and strongly agree that they can memorize English words faster with mnemonic.

Table 8. Students Understanding towards English Words Increased After Being Introduced to Mnemonic Technique

\begin{tabular}{llcccc}
\hline & Frequency & Percent & Valid percent & Cumulative percent \\
\hline Valid & Neither agree nor disagree & 4 & 12.1 & 12.1 & 12.1 \\
& Agree & 16 & 48.5 & 48.5 & 60.6 \\
& Strongly agree & 13 & 39.4 & 39.4 & 100.0 \\
& Total & 33 & 100.0 & 100.0 & \\
\hline
\end{tabular}

Furthermore, the highest percentage of answers for the next statement is $48.5 \%$ of the respondents agree that their understanding towards English words has increased after being introduced to mnemonic technique. The lowest percentage of answers for this statement is $12.1 \%$ where the respondents neither agree nor disagree about this matter. The rest of them choose to strongly agree with the statement in the percentage of $39.4 \%$ among all of the respondents. This shows that most of the respondents realized that their understanding towards English words has increased after being introduced to mnemonic technique. Based on the researcher's observation during the two teaching and learning sessions made by the English teacher for the students, there are some differences happened to the students noticed by the researcher. 
Besides that, the result of the mini quiz after the teaching and learning session also has improved after the students are provided with a picture for each word. This time, about 12 of the students get full marks, four of them collect 29 marks, five get 28 marks, one student obtains 27 marks, two of them score 26 marks with the last five get the 25 marks. This shows that the total number of students who score above 25 has increased from 14 to 29 students. All of these results are improved due to the use of visual mnemonic in teaching and learning the English vocabulary. The researcher provides some observation report during the teaching and learning session which is made especially for this research objective. The researcher explains on the students' behavior while learning the English vocabulary and how they do in the mini quiz provided after each learning session, which one of it involves mnemonic technique and the other is just by using the normal way of teaching.

\section{Conclusion}

It is shown from the past researches that mnemonic techniques have a positive effect in the application of learning the English vocabulary. Some of the positive effects are developing a firm link between the new vocabulary item and its meaning, expanding the vocabulary of a speaker, increasing the performance of a student and many more.

The main objective of this research is to identify the impacts of using mnemonic techniques in learning English vocabulary among the primary school students of Sekolah Kebangsaan Sungai Udang (SKSU). The researcher has gained several types of impact by using mnemonic techniques in learning English vocabulary. The impacts are explained by the findings of the researcher that gets from the questionnaire after the two sessions of teaching English vocabulary are conducted.

According to the result collected from the questionnaire on the section "impact of the mnemonic technique in learning English vocabulary", most of the respondents agree that they love the mnemonic techniques more compared to the normal teaching technique. This result may come based on a few reasons. As stated by Chan (2000), it believes that the autonomy of employing either imagery or the sentence can be enjoyed by the learners, which ever snaps into the mind and appears to be the most regular way of creating the association. It means that the learner may enjoy the learning process by using the mnemonic technique.

Besides that, it has been reported by a few studies that the mnemonic method is superior for vocabulary learning to other traditional methods like the context method since the introduction of the mnemonic method by Atkinson (1975) and his colleagues as an effective supplementary technique for foreign vocabulary learning (Mastropieri, 1990). It can also supported with the study done by Anjomafrouzi and Tajalli (2012) where the data shows that a better performance of adult students is created with the use of mnemonic associations compared to the external control (rote group) and internal control group (when students used no association in mnemonics group).

Furthermore, most of the respondents also agree that they can memorize more of English words with the mnemonic. This is the after effect which they get from learning the English vocabulary by using the mnemonic technique. The result is the same as what Lorayne and Lucas (1974) and Spackman (2009) claim that retrieving the image can help strengthen the memory such that it can be remembered for as long as necessary by refreshing the image occasionally. This kind of aid is in line with DeLashmutt (2007) opinion in her research when it is suggested the factor comprehension scores were higher for students who used mnemonic strategies because the strategy raised their ability to retrieve the factual information needed to answer a typical comprehension question.

Next, the majority of the respondents agree that mnemonic techniques can widen students' English vocabularies. There are a few researchers that also agree with this finding as they claim that in expanding the vocabulary of English native speakers, mnemonic technique can also be effective (Amiryousefi, 2011).). This opinion also can be used for the students who are not native speaker because they also learn the new words in the same kind of language.

The other finding of the questionnaire on the impact of using mnemonic techniques in learning English vocabulary is the majority of the respondents decide that they can memorize English words faster when using mnemonic techniques in learning English vocabularies. This result can be supported by Chan (2000) learning that takes place at a quicker rate when the catalysts are pictures rather than when they are words. It also believes that the mnemonic or keyword method will assist to grow a firm link between the new vocabulary item and its meaning, which enables learners to better regain the appropriate word at the accurate moment.

Other than that, the researcher has found that most of the respondents accept that they only need to remember the simple clue to memorize the English words. This majority answer is related to Spackman (2009) opinion, where it says that mental images are not limited to the keyword method because most visually-oriented mnemonic systems use them. Moreover, it also claims that the original word and its meaning can be recalled by recalling the keyword (Spackman, 2009). Thus, it is shown from other researchers that mnemonic technique can make primary school students to only memorize a simple clue in order to memorize the English vocabulary.

The last finding which the researcher obtains from the questionnaire is most of the respondents can remember the English words for longer time after they have been introduced to the mnemonic technique. In order to support this finding, there are some statements from other researchers such as Benge and Robbin (2009) where researchers have discovered the value of mnemonics with a variety of groups, examining both immediate and long-term retention, and with mnemonic materials developed by teachers, students and experts. Baleghizadeh (2010) and Spackman (2009) also explain that occasionally refreshing the image by retrieving it helps strengthen the memory such that it can be remembered for as necessary. According to the study made by Sarcoban and Basibek (2012), mnemonic methods 
specifically promotes vocabulary retention of the elementary level of EFL. Thus, mnemonic techniques are suitable for leading the memory to longer term retention of the vocabulary items of elementary and true beginner language learners.

Based on the observation and questionnaire given to the respondents, the researcher has made a few conclusions about the effectiveness of using mnemonic techniques in learning English vocabulary among primary school students. The first objective is to identify the impact of using mnemonic techniques in learning English vocabulary.

The first impact of using mnemonic techniques in learning English vocabulary is the students love the mnemonic techniques more compared to the normal teaching technique. The differences can be seen from the interest of students in answering the mnemonic exercise on those two days. Next is the student can memorize more English words with the mnemonic. This conclusion is created when the respondents got a higher score in doing the exercise by using mnemonic techniques compared to the regular way of teaching the English vocabulary. Another impact is the English vocabulary of the students also can be widened by using the mnemonic technique. This is due to the students learning new words as they are entering a new chapter for their English syllabus. Thus, the mnemonic technique will help them in remembering those new words that they will learn in each new chapter.

Besides that, the rate of time taken to memorizing the English words by using the mnemonic technique also increased after they have done the two sessions of memorizing the set of English vocabularies. This result is obtained when some of the respondents tend to answer the questions faster on the second day as they are taught to memorize the English vocabulary by using the mnemonic technique; which are the words are brought together with a picture on top of them. The next impact is students only need to remember the simple clue to memorize the English words. This is due to the researchers' technique, the students are asked to memorize the English vocabulary together with the picture provided for each word in the mnemonic teaching and learning session. Thus, they only need to remember the image of the word in order to memorize the new English vocabulary. Lastly, most of the students agree that they can memorize the English words in longer time.

\section{References}

Allen, J. (1999). Words, words, words: Teaching vocabulary in grades 4-12. Stenhouse Publishers.

Amiryousefi, M., \& Ketabi, S. (2011). Mnemonic instruction: A way to boost vocabulary learning and recall. Journal of Language Teaching and Research, 2(1), 178-182.

Baleghizadeh, S., \& Ashoori, A. (2010). The effect of keyword and word-list methods on immediate vocabulary retention of EFL learners. Pakistan Journal of social sciences (PJSS), 30(2), 251-261.

Beck, I. L., McKeown, M. G., \& Kucan, L. (2013). Bringing words to life: Robust vocabulary instruction. Guilford Press.

Benge, C., \& Robbins, M. E. (2009). Using keyword mnemonics to develop secondary students' vocabularies: A teacher's action research. Journal of Language and Literacy Education, 6(1), 93-104.

Brown, T. S., \& Perry, F. L. (1991). A comparison of three learning strategies for ESL vocabulary acquisition. Tesol Quarterly, 25(4), 655-670.

Chan, L. P. (2000). An investigation of the effectiveness of the mnemonic technique in theacquisition and retrieval of vocabulary by Chinese-speaking Form Onestudents. 香港大學學位論文, 1-0.

Congos, D. (2005) 9 Types of Mnemonics for Better Memory. Retrieved on November 11, 2013, from www.learningassistance.com/2006/january/mnemonics.html.

Craik, F. I., \& Lockhart, R. S. (1972). Levels of processing: A framework for memory research. Journal of verbal learning and verbal behavior, 11(6), 671-684.

Deconinck, J., Boers, F., \& Eyckmans, J. (2010). Helping learners engage with L2 words: The form-meaning fit. Aila Review, 23(1), 95-114.

DeLashmutt, K. (2007). A study of the role of mnemonics in learning mathematics. (Unpublished master thesis), University of Nebraska, Lincoln.

Erten, İ. H., \& Tekin, M. (2008). Effects on vocabulary acquisition of presenting new words in semantic sets versus semantically unrelated sets. System, 36(3), 407-422.

Gu, Y., \& Johnson, R. K. (1996). Vocabulary learning strategies and language learning outcomes. Language learning, 46(4), 643-679.

Hatch, E., \& Brown, C. (1995). Vocabulary, Semantics, and Language Education. Cambridge University Press.

Hauptmann, J. (2004). The effect of the integrated keyword method on vocabulary retention and motivation (Doctoral dissertation, Education).

Hayes, O. C. (2009). The Use of Melodic and Rhythmic Mnemonics to Improve Memory and Recall in Elementary Students in the Content Areas. Online Submission.

Joe, A. (1998). What effects does text-based task promoting generation have on incidental vocabulary acquisition? Applied Linguistics, 19(3), 357-377. 
Kelly, P., \& Li, X. H. (2005). A new approach to learning English vocabulary: more efficient, more effective, and more enjoyable. Beijing: Foreign Language Teaching and Research Press.

Lorayne, H., \& Lucas, J. (1974). The memory book. New York: Stein and Day

Ma, Q. (2009). Second language vocabulary acquisition. Bern: Peter Lang.

Mastropieri, M. A., Scruggs, T. E., \& Fulk, B. J. M. (1990). Teaching abstract vocabulary with the keyword method: Effects on recall and comprehension. Journal of Learning Disabilities, 23(2), 92-96.

Meara, PM. (1996), The dimensions of lexical competence. In: G Brown, K Malmkjaer and J Williams (Eds.) Competence and Performance in Language Learning. Cambridge: Cambridge University Press.

Miller, G.A and Wakefield, P.C. (1993) Commentary on Anglin's analysis of vocabulary growth. In Anglin: 167-175. [7.2]

Nunan, D. (1991). Language teaching methodology. London: Prentice-Hall.

O’Malley, J.M. and A. Chamot. (1990). Strategies used by Second Language Learners Cambridge: CUP.

Oxford, R.L., (1990), Language Learning Strategies: What Every Teacher Should Know. Boston: Heinle \& Heinle

Presslry, M., Levin, J. R., \& Delaney, H. D.(1982). The mnemonic keyword method. Review of Educational Research, 52, 61-91.

Raugh, M. R., \& Atkinson, R. C. (1975). A Mnemonic Method for Learning a Second-Language Vocabulary. Journal of Educational Psychology, 67(1), 1.

Sariçoban, A., \& Basibek, N. (2012). Mnemonics technique versus context method in teaching vocabulary at upperintermediate level. Egitim ve Bilim, 37(164), 251.

Scruggs, T. E., \& Mastropieri, M. A. (2000). The effectiveness of mnemonic instruction for students with learning and behavior problems: An update and research synthesis. Journal of Behavioral Education, 10(2-3), 163-173.

Spackman, C. L. (2009). Mnemonics and Research on Using the Keyword Method in the Classroom.

Thompson, I. (1987). Memory in language learning. In A. Wenden, \& J. Rubin (Eds), Learner strategies in language learning (pp. 43-56). New Jersey: Prentice-Hall.

Wenden, A. \& Rubin, J. (eds). (1987). Learner Strategies in Language Learning Hemel Hempstead: Prentice Hall International

Winitz, H. (1978). Comprehension and language learning. In C.H. Blatchford \& J. Schachter (Eds). On TESOL "78: EFL policies, programs, practices, (pp. 49-56). Washington, DC: TESOL

Zhang, G.P. (1996). Improving vocabulary teaching in intensive reading. Teaching English in China, 27, 42-43. 